\title{
Comparison of postmenopausal voice changes across professional and non-professional users of the voice
}

\author{
Pallavi Sovani \\ Institute for Psychological Health, Thane and Hiranandani Hospital, Thane, Maharashtra, India
}

Geetha Mukundan

Ali Yavar Jung National Institute for the Hearing Handicapped, Mumbai, India

Correspondence to: PSovani (pallavi_mail2003@yahoo.co.in)

\begin{abstract}
Menopause effects a permanent change in certain body functions, including voice. If the voice is used continually as part of one's occupation, this may further impact on postmenopausal voice changes. The present study investigated individual and combined effects of menopause and professional voice use on voice. Ninety-two women were classified into reproductive (52) and postmenopausal (40) groups. Each group was divided into level II (teachers) and level IV (clerks) of Koufman and Isaacson's (1991) classification. Voice samples were recorded and analysed using the VisiPitch III software. Aerodynamic parameters were manually calculated. The Voice Handicap Index (VHI) was included to improve face validity of the study. Results suggest that fundamental frequency $\left(\mathrm{F}_{\mathrm{o}}\right)$, speaking fundamental frequency $\left(\mathrm{SF}_{\mathrm{o}}\right)$ and maximum phonation time (MPT) decrease after menopause while noise-to-harmonic ratio and voice turbulence index increase. Being a professional voice user seems to affect the nature of postmenopausal voice changes, since an interaction effect was observed for some voice parameters. VHI scores reflect that teachers are aware of voice problems caused by vocal abuse, though relatively unaware of postmenopausal voice changes. The study has implications for improving the working conditions of teachers in India, developing norms for menopausal changes and modifying allowable limits for voice recognition systems in future.
\end{abstract}

Keywords: acoustic, aerodynamic, menopause, voice, voice handicap index

Voice production requires an intact vocal mechanism comprising laryngeal tissues, cartilage and muscles, and the elastic and pliable vocal folds. The laryngeal mechanism is extremely vulnerable to a large number of factors such as vocal abuse or misuse, drugs, allergies, infection, alcohol or smoking, and also several non-pathological factors such as the proportion of various hormones in the body. According to Boone (1997), the larynx is heavily influenced by hormonal changes within the individual, especially during puberty, and during and after menopause.

Menopause is defined as the time when there have been no menstrual periods for 12 consecutive months and no other biological or physiological cause can be identified (Conrad-Stoppler, 1999). Age of onset of menopause varies according to race, climate and dietary habits. Research on menopause is even more important in the Indian scenario, as the mean age for menopause in Indian women is lower than the mean age worldwide (Syamala \& Sivakami, 2007).

Early research on menopause involved singers with amenorrhoea, and showed that common vocal complaints among these singers included a crack in the voice, breathiness/weakness, an inability to phonate on certain pitches, and an inability to adequately support tones (Sataloff, 1998). Other studies on menopause and the singing voice include those of Emerich, Hoover and Sataloff (1996), and Abitbol, Abitbol and Abitbol (1999). Abitbol et al.'s study listed loss of power, vocal fatigue, decreased range and a loss of high notes among the changes associated with menopause.

Boulet and Oddens (1996) studied female voice changes around and after menopause. Their subjects comprised 48 female and 24 male professional singers aged $40-74$ years. A questionnaire was used to determine whether women's and men's voice changes were different, and to indicate whether menopause had an impact on the female voice. Both men and women were of the opinion that the voice generally underwent changes at around age 50, but the female singers placed greater emphasis on problems affecting the high registers and voice control than the men. Both sexes reported huskiness, but the women seemed to have more frequent problems with voice emission, voice control and reaching their highest registers. Meurer, Wender, Corleta and Capp (2003) studied phono-articulatory variations in women of reproductive age (30 - 40 years) and postmenopausal women. Results showed a greater variability in vocal sustenance, less variation in formants, and verbal variations in diadochokinesis in postmenopausal women. These studies indicate that although changes in voice may occur as a result of ageing in men and women, the female voice does undergo specific changes around the time of menopause.

The impact that a change in voice may have on an individual's life may depend on many factors, one factor being the extent of voice use (Yiu, 2002; Zeine \& Waltar, 2002). Koufman and Isaacson (1991) suggested a 'vocal usage' classification system. This is a comprehensive classification encompassing a wide range of vocal use, and has been alluded to in earlier research studies (Timmermans, De Bodt, Wuyts, Boudewijins, Clement, Peeters, et al., 2002). A recent study by Cheng and Woo (2010) utilised another method of classification in the form of a rating scale from 0 (low use) to 5 (elite use). However, the Koufman and Isaacson classification appears to be a more specific, well-defined system, comprising four levels:

Level I: The elite vocal performer - including professional singers and actors, for whom even slight vocal difficulty may cause serious consequences.

Level II: The professional voice user - including clergy, public speakers, lecturers, telephone operators, for whom moderate vocal difficulty would prevent adequate job performance.

Level III: The non-vocal professional - comprising doctors, lawyers, business persons, sales persons, etc. who cannot perform their work properly if suffering from severe dysphonia.

Level IV: Includes factory workers, labourers, clerks, who would not be prevented from doing their work if suffering from vocal difficulties.

Stemple, Glaze and Gerdeman (1995) define professional voice users as the group of individuals who, by the very nature of their occupation, are directly dependent on vocal communication for their livelihood. Their voice problems can be labelled occupational voice disorders since the symptoms they suffer from are likely to be caused by the type of work. Early studies on professional voice users involved mainly actors (Novak, Dlouha, Capkova \& Vohradnik, 1991) and singers (Sheela, 
1974; Ragini, 1986), i.e. the 'artistic' professional voice users. These studies established that elite vocal performers have to stretch their voice beyond average limits, a finding reaffirmed by Sataloff (1991). Level II professionals, however, were given relatively less importance. This was in spite of the fact that among professional voice users, teachers form the biggest group and are at maximum risk for developing voice disorders (Buekers, Bierens, Kingma \& Marres, 1995; Simberg, Sala \& Ronnemaa, 2004). Factors such as number of students, classroom design, ergonomics (resulting in faulty posture), dusty environment (especially chalk dust), background noise and teachers' additional duties also act against vocal hygiene.

Voice abuse in teachers was investigated by Rantala, Vilkman and Bloigu (2002), who found an increase in Fundamental Frequency $\left(\mathrm{F}_{\mathrm{o}}\right)$ during the working day. Soderstein, Granqvist, Hammarberg and Szabo (2002) who studied preschool teachers found that on average, the teachers spoke $9.1 \mathrm{~dB}$ louder and with a higher mean $\mathrm{F}_{\mathrm{o}}$ at work than the baseline for $\mathrm{F}_{\mathrm{o}}$ during other speech tasks. Simberg et al. (2004) compared the prevalence of vocal symptoms among students studying to be teachers and other university students. The student teachers reported a greater number and frequency of vocal symptoms. In a study on respiratory and laryngeal function of teachers with and without voice disorders, Lowell, Barkmeier-Kraemer, Hoit and Story (2008) used the Voice Activity and Participation Profile (VAPP) (Ma \& Yiu, 2001), a tool that evaluates subjects' perception of impact of the voice problem on various areas of their lives. VAPP scores for the voice-disordered group were significantly greater than those for the control group. The four studies discussed above have two important implications: firstly, that teaching is a vocally demanding profession, and secondly, the use of self-assessment questionnaires brings forth the degree to which teachers are aware of their vocal discomfort, and the degree to which they are affected by it.

In professional voice users, the voice disorder not only causes vocal symptoms but also carries with it a high level of emotional strain and anxiety as a result of the inability to perform their job (Stemple et al., 1995). Quality of life (QoL) measures provide a better insight into these difficulties and recognise the centrality of the patient's point of view. One such subjective measure is the Voice Handicap Index (VHI) (Jacobson, Johnson, Grywalsky, Silbergleit, Jacobson, Benniger, et al., 1997), a standardised self-assessment ordinal scale to subjectively assess the amount of difficulty a voice disorder is causing. It consists of 30 questions representing different problems in speaking situations, with the person required to rate the frequency of the problem on a 5-point scale (from 0 to 4 ). Each question tests one of three aspects, resulting in three subscale scores - functional, physical and emotional (maximum possible for each subscale $=40)$ - and a total score (maximum possible score $=120$ ). The VHI has been widely used for research purposes (Rosen, Murry, Zinn, Zullo \& Sonbolian, 2000; Wheeler, Collins \& Sapienza, 2006). It has also been translated into and validated in other languages such as Portuguese (Guimaraes \& Abberton, 2004) and Hebrew (Amir, Ashkenazi, Leibovitzh, Michael, Tavor \& Wolf, 2006).

QoL measures have been used with objective measures by various researchers, leading to the conclusion that these subjective assessment tools are affected by factors other than voice quality (Murry, Medrado, Hogikyan \& Jonathan, 2004); that they effectively measure functional therapeutic outcomes (Rosen et al., 2000); and that objective and subjective measures give independent information in practice (Wheeler et al., 2006). These studies suggest that assessment using a subjective tool is necessary for gauging the impact of vocal difficulties experienced by subjects.

Female teachers are likely to experience vocal difficulties when they undergo menopause. The extent of voice use in their profession would also affect their voice. In fact, the two factors might interact. Russell, Oates and Greenwood (1998) found that female teachers are twice as likely as male teachers to report voice problems, a finding that suggests the influence of factors other than occupational voice use. The researchers stressed the need for further investigation of the causes of vocal dysfunction in teachers. However, studies on menopause and the professional voice have generally focused on level I professionals (actors, singers).

Although the scope of voice therapy is rapidly widening in order to cater to the special population of 'professional voice users', including level II professionals, few studies have attempted to document voice changes due to menopause, or their interaction with occupational voice use, in this population. No norms have been cited in literature to account for voice changes due to menopause. In spite of the earlier age for menopause in Indian women, not enough efforts are being made to conduct research and forewarn women about postmenopausal voice changes so as to reduce their potential psychosocial impact. Hence the present study was aimed at investigating the changes in acoustic and aerodynamic voice parameters of women who are professional voice users versus those who are non-professional voice users, following menopause. It also aimed at probing the relevance of these findings to the population concerned using a subjective assessment tool, since subjective measures greatly add to the face validity of the study (in that they help reflect upon the actual problems faced by the subjects) and in turn, the value of the study.

\section{Method}

The data were collected on visits to schools and offices across Mumbai and interacting with teachers and clerks/accountants respectively, after seeking permission from their employers. A 'brief voice history' questionnaire (Colton \& Casper, 1990) was administered to potential subjects. This was to elicit information on various general and systemic variables such as illnesses, allergies, medications, surgery, nature and amount of voice use at work, etc. Two questions - pertaining to 'marital status' and 'time elapsed post menopause (if menopause had occurred)' - were added to the questionnaire. Based on responses to the questionnaire, the subjects were screened for all the inclusion criteria and could be assigned to an appropriate group (Table I). In this way, a purposive sample of 92 subjects was included in the study. A $2 * 2$ quasiexperimental research design was used, and subjects were classified according to two independent variables - menopause (reproductive age and postmenopausal) and professional voice use (level II of Koufman and Isaacson's classification represented by teachers and level IV represented by clerks). The group distribution is shown in Table I.

Table I. Distribution of subjects into groups

\begin{tabular}{|c|c|c|}
\hline & Level II (teachers) & Level IV (clerks) \\
\hline Reproductive age & 32 & 20 \\
\hline Postmenopausal & 20 & 20 \\
\hline
\end{tabular}

\section{Inclusion criteria}

For women of reproductive age:

1. Age range: 30 - 35 years

2. Regular menstrual cycles

3. At least a week elapsed since the onset of the previous menstrual cycle

4. The next menstrual cycle has not yet commenced

5. Marital status: married.

For postmenopausal women:

1. Minimum age limit: 45 years

2. Marital status: married

3. 1 - 5 years elapsed since cessation of menstruation

4. Marital status was a criterion because the vocal demands and stressors in the life of married and unmarried women can be expected to be different (Ravichandran \& Rajendran, 2007), and controlling this variable could increase the internal validity of the study.

\section{Exclusion criteria}

1. Use of oral or injectable contraceptives, hormonal medication or hormonal therapy 
2. Subjects with upper respiratory tract infection, especially during recording

3. Subjects with a history of smoking, chronic alcoholism, asthma, or vocal cord pathologies.

\section{Procedure}

Validation of the digital voice recorder

A pilot study was conducted with 20 young normal healthy adults as subjects (10 male, 10 female) and acoustic parameters obtained from online analysis and analysis of recordings using a Sony ICD-P620 digital voice recorder were compared using Student's $t$-test. No significant difference between the two sets of values was obtained for any of the parameters. Shimmer for the recorded sample was slightly higher, but the difference was not significant.

\section{Administration of the Voice Handicap Index}

The VHI (Jacobson et al., 1997) was the most readily available tool used regularly as part of the clinical voice evaluation at Ali Yavar Jung National Institute for the Hearing Handicapped (AYJNIHH), Mumbai, i.e. the place of research. The subjects were given the VHI to investigate their perceptions of changes in voice, if any. They were given the following instructions: 'Answer the questions by marking the appropriate option according to the frequency of the problems stated (an example was given using the first question). Rate the frequency of the problem on a 5 -point scale, where $0=$ never; $1=$ almost never; $2=$ sometimes; 3 = almost always; $4=$ always.

\section{Obtaining voice samples}

The voice samples were obtained, with informed consent, using a Sony ICD-P620 digital voice recorder. The subject was asked to sit comfortably in a quiet room. The microphone was held by the researcher at a mouthto-microphone distance of $15 \mathrm{~cm}$, at an angle of 45 degrees. The subject was asked to perform three tasks:

- To phonate /a/, /i/ and $/ \mathrm{u} /$ sounds at comfortable pitch and loudness.

- To read the first three lines of Fairbanks' 'rainbow passage' (Fairbanks, 1960) out of which the second line was chosen for analysis, to avoid any special effects associated with initial and final sentences and yet provide tolerable accuracy (Baken \& Orlikoff, 2000).

- To introduce herself when asked the question 'What is your name?'

The acoustic voice parameters were then obtained using the multidimensional voice profile (MDVP) program of the VisiPitch III software at AYJNIHH, Mumbai.

\section{Aerodynamic measures}

The subjects were asked to prolong an /a/ sound for as long as they could. The better of two trials was taken as the maximum phonation time (MPT), measured using a stopwatch.

The subjects were asked to prolong an /s/ sound for as long as they could. They were then asked to try to produce a $/ \mathrm{z} /$. For subjects who could manage to produce a $/ \mathrm{z} /$ sound the $\mathrm{s} / \mathrm{z}$ ratio was calculated ( 65 of them could not produce a $/ \mathrm{z} /$, since the sound does not belong to the phonology of many Indian languages).

\section{Statistical analysis}

Two-way ANOVA (analysis of variance) was used to find out if a significant difference exists across menopause, profession, and whether any interaction effect was present. An additional analysis was done using ANCOVA (analysis of covariance), to see whether the significant difference in voice parameters due to menopause persisted after covarying out the effects of age.

\section{Results}

\section{Acoustic parameters}

\section{Fundamental frequency $\left(F_{o}\right)$}

The overall trend seen in the findings was that the $F_{o}$ appeared to decrease after menopause, as shown in Table II. On statistical analysis using two-way ANOVA, the $\mathrm{F}_{\mathrm{o}}$ of postmenopausal women was significantly lower for $/ \mathrm{a} /[\mathrm{F}(1,88)=21.43, p<0.001], / \mathrm{i} /[\mathrm{F}(1,88)=11.04$, $p<0.001]$ and $/ \mathrm{u} /[\mathrm{F}(1.88)=11.15, p<0.001]$ than women of reproductive age. For all three vowels, there was no significant difference in $\mathrm{F}_{\mathrm{o}}$ across the two levels of voice use, i.e. between teachers (level II) and clerks (level IV). However, an interaction effect was seen between professional voice use and menopause. To further investigate this interaction, an independent-samples $t$-test was first conducted between level II and level IV professionals within the reproductive group. The test was then repeated within the postmenopausal group. In the reproductive group, the $\mathrm{F}_{\mathrm{o}}$ of the teachers was found to be significantly lower. However, the difference between $\mathrm{F}_{\mathrm{o}}$ of level II and level IV professionals was not significant in the postmenopausal group. This meant that the $\mathrm{F}_{\mathrm{o}}$ reduction after menopause in teachers was less than that of the clerical population.

\section{Relative average perturbation (RAP) (\%)}

There were no specific trends seen in the data for RAP values. Statistical analysis using two-way ANOVA revealed no significant differences either across profession or across menopause, for any of the vowels tested. No significant interaction was seen between profession and menopause.

Table II. Means and SDs of $\mathrm{F}_{\mathrm{o}}$ values (in $\mathrm{Hz}$ ) for sustained phonation across the different groups of level II and level IV professionals

\begin{tabular}{|c|c|c|c|c|c|c|c|}
\hline \multirow[b]{2}{*}{ Category } & & \multicolumn{2}{|c|}{$/ a /$} & \multicolumn{2}{|c|}{ /i/ } & \multicolumn{2}{|c|}{$/ \mathbf{u} /$} \\
\hline & & Level II & Level IV & Level II & Level IV & Level II & Level IV \\
\hline Reproductive age & Mean & 207.21 & 222.99 & 207.01 & 228.05 & 213.99 & 226.88 \\
\hline & $\mathrm{SD}$ & 19.55 & 20.27 & 20.95 & 19.39 & 19.07 & 20.51 \\
\hline Postmenopausal & Mean & 194.24 & 193.68 & 201.93 & 198.27 & 206.86 & 199.10 \\
\hline & SD & 14.54 & 29.74 & 18.78 & 32.44 & 16.52 & 34.92 \\
\hline
\end{tabular}

$\mathrm{SD}=$ standard deviation; $\mathrm{F}_{\mathrm{o}}=$ fundamental frequency

Table III. Means and SDs of NHR values for sustained phonation of $/ \mathbf{a} /, / \mathbf{i} /$ and $/ \mathbf{u} /$ across the different groups studied

\begin{tabular}{|c|c|c|c|c|c|c|c|}
\hline \multirow[b]{2}{*}{ Category } & & \multicolumn{2}{|c|}{$/ \mathbf{a} /$} & \multicolumn{2}{|c|}{$/ \mathbf{i} /$} & \multicolumn{2}{|c|}{$/ \mathbf{u} /$} \\
\hline & & Level II & Level IV & Level II & Level IV & Level II & Level IV \\
\hline \multirow{2}{*}{ Reproductive age } & Mean & 0.17 & 0.14 & 0.22 & 0.22 & 0.18 & 0.19 \\
\hline & SD & 0.07 & 0.03 & 0.09 & 0.12 & 0.10 & 0.10 \\
\hline \multirow[t]{2}{*}{ Postmenopausal } & Mean & 0.18 & 0.17 & 0.27 & 0.26 & 0.27 & 0.15 \\
\hline & SD & 0.07 & 0.06 & 0.11 & 0.19 & 0.14 & 0.04 \\
\hline
\end{tabular}

$\mathrm{SD}=$ standard deviation; $\mathrm{NHR}=$ noise-to-harmonic ratio. 
Table IV. Means and SDs of VTI values for sustained phonation of $/ \mathbf{a} /, / \mathbf{i} /$ and $/ \mathbf{u} /$ across the different groups studied

\begin{tabular}{|c|c|c|c|c|c|c|c|}
\hline \multirow[b]{2}{*}{ Category } & & \multicolumn{2}{|c|}{$/ \mathbf{a} /$} & \multicolumn{2}{|c|}{$/ \mathbf{i} /$} & \multicolumn{2}{|c|}{$/ \mathbf{u} /$} \\
\hline & & Level II & $\overline{\text { Level IV }}$ & Level II & $\overline{\text { Level IV }}$ & Level II & Level IV \\
\hline Reproductive age & Mean & 0.04 & 0.03 & 0.08 & 0.07 & 0.02 & 0.02 \\
\hline & SD & 0.01 & 0.01 & 0.03 & 0.07 & 0.01 & 0.01 \\
\hline Postmenopausal & Mean & 0.05 & 0.04 & 0.16 & 0.06 & 0.05 & 0.02 \\
\hline & SD & 0.02 & 0.01 & 0.09 & 0.03 & 0.03 & 0.01 \\
\hline
\end{tabular}

$\mathrm{SD}=$ standard deviation; $\mathrm{VTI}=$ voice turbulence index .

\begin{tabular}{|c|c|c|c|c|c|}
\hline \multirow[b]{2}{*}{ Category } & \multirow[b]{3}{*}{ Mean } & \multicolumn{2}{|c|}{ Reading (Rainbow passage) } & \multicolumn{2}{|c|}{ Spontaneous speech } \\
\hline & & Level II & Level IV & Level II & Level IV \\
\hline \multirow[t]{2}{*}{ Reproductive age } & & 220.15 & 226.37 & 220.86 & 228.49 \\
\hline & SD & 20.11 & 21.56 & 20.98 & 21.83 \\
\hline \multirow{2}{*}{ Postmenopausal } & Mean & 206.92 & 201.70 & 205.30 & 203.89 \\
\hline & SD & 15.19 & 21.70 & 16.59 & 22.60 \\
\hline
\end{tabular}

$\mathrm{SD}=$ standard deviation; $\mathrm{SFo}=$ speaking fundamental frequency.

\section{Shimmer (dB)}

Like RAP, overall there were no specific trends seen for shimmer. When two-way ANOVA was used, there was no significant difference in shimmer across menopause, or across profession.

\section{Noise-to-harmonic ratio (NHR)}

Overall, the NHR values appeared to increase after menopause. Also, NHR values for professional voice users appeared to be higher than those for non-vocal professionals. However, these differences were not statistically significant, and there was no interaction effect. The means and standard deviations (SDs) are displayed in Table III.

A common trend seen between NHR and perturbation measures was that the values for $/ \mathrm{i} /$ and $/ \mathrm{u} /$ were greater than those of $/ \mathrm{a} /$.

\section{Voice turbulence index (VTI)}

A significant increase was found in the VTI after menopause when teachers and clerks were considered as one group. However, when a $t$-test was done separately on the clerical population, there was no significant difference in the VTI values of clerks after menopause. This implies that the significant increase in VTI after menopause for all the women taken together was due to the increase in VTI values of teachers after menopause. The attributes of menopause and professional voice use were therefore seen to interact here, a finding confirmed by an interaction effect on the two-way ANOVA. The VTI values for /i/ were the greatest among the three vowels tested. Means and SDs are given in Table IV.

\section{Speaking fundamental frequency $\left(S F_{o}\right)$}

The mean $\mathrm{SF}_{\mathrm{o}}$ value for the reproductive age group in the present study was $223.26 \mathrm{~Hz}$. $\mathrm{SF}_{\mathrm{o}}$, like $\mathrm{F}_{\mathrm{o}}$ for phonation, tended to decrease after menopause. This was true for both clerks and teachers, for both the types of stimuli used. The means and SDs are displayed in Table V.

When the data were subjected to analysis using two-way ANOVA, a significant difference was seen in the $\mathrm{SF}_{\mathrm{o}}$ values between women of reproductive age and postmenopausal women for both reading $[\mathrm{F}(1.88)=20.09, p<0.001]$ and spontaneous speech $[\mathrm{F}(1.88)=20.79$, $p<0.001]$ samples. No significant difference was obtained between the $\mathrm{SF}_{\mathrm{o}}$ values of the two professional groups. Being a professional voice user seemed to affect postmenopausal changes in $\mathrm{SF}_{\mathrm{o}}$ in that changes in teachers were smaller than those in clerks. However, the interaction effect was not statistically significant. An incidental finding was that there was no significant difference in $\mathrm{SF}_{\mathrm{o}}$ obtained for both the tasks when verified using an independent-samples $t$-test.

\section{Aerodynamic parameters}

Maximum phonation time (MPT) (seconds)

The data showed that there was a slight reduction in MPT after menopause. Also, the MPT values for teachers were lower than those of clerks. However, both these differences were not statistically significant. No interaction effect was seen. Mean and SD values are displayed in Table VI.

Table VI. Means and SDs of MPT values (in seconds) across the different groups studied

\begin{tabular}{llll}
\hline Category & & Level II & Level IV \\
Reproductive age & Mean & 11.87 & 13.45 \\
& SD & 4.98 & 4.47 \\
Postmenopausal & Mean & 11.05 & 12.80 \\
& SD & 3.47 & 5.20
\end{tabular}

$\mathrm{SD}=$ standard deviation; $\mathrm{MPT}=$ mean phonation time

\section{$s / z$ ratio}

There were no particular trends observed in the $\mathrm{s} / \mathrm{z}$ ratio for either professional or non-professional voice users, probably because of the limited data. Two-way ANOVA revealed no effects of menopause or profession, and no interaction effect, on the $\mathrm{s} / \mathrm{z}$ ratio.

\section{Voice Handicap Index (VHI)}

One extremely apparent trend was that VHI (Jacobson et al., 1997) scores (total as well as subscale) were much greater in level II professionals than in level IV professionals. Another interesting finding was that for both teachers and clerks, the VHI scores were greater in the reproductive age group, and lower in the postmenopausal group, although the difference was not statistically significant. Two-way ANOVA revealed a highly significant difference across the two levels of voice use, i.e. across clerks and teachers, for the total VHI score $[\mathrm{F}(1.88)=17.53, p<0.001]$ as well as for the functional $[\mathrm{F}(1,88)=6.20, p<0.01]$, physical $[\mathrm{F}(1.88)=26.02$, $p<0.001]$ and emotional $[\mathrm{F}(1.88)=9.89, p<0.002]$ subscale scores. No significant interaction effect was observed. The results are displayed in Table VII.

\section{Discussion}

\section{Acoustic parameters}

The mean $\mathrm{F}_{\mathrm{o}}$ of all the women (teachers and clerks) in the reproductive age group for vowel /a/ was $213.28 \mathrm{~Hz}$. When compared with the mean $\mathrm{F}_{\mathrm{o}}$ obtained in a study by Till, Jafari, Crumley and Law-Till (1992), precisely $221.2 \mathrm{~Hz}$, the mean in the present study appears to be lower. This could be because the population in Till et al.'s (1992) study 
Table VII. Means and SDs of VHI total and subscale scores across the different groups studied

\begin{tabular}{|c|c|c|c|c|c|}
\hline \multirow{3}{*}{ VHI scores } & \multirow{4}{*}{$\begin{array}{l}\text { Mean } \\
\text { SD }\end{array}$} & \multicolumn{2}{|c|}{ Reproductive age } & \multirow{2}{*}{\multicolumn{2}{|c|}{$\frac{\text { Postmenopausal }}{\text { Level II Level IV }}$}} \\
\hline & & \multirow{3}{*}{$\begin{array}{l}\text { Level II } \\
14.96 \\
14.12\end{array}$} & \multirow{2}{*}{$\begin{array}{l}\text { Level IV } \\
4.6\end{array}$} & & \\
\hline & & & & 10.90 & 3.65 \\
\hline & & & 3.8 & 9.34 & 4.99 \\
\hline Functional & Mean & 5.15 & 2.65 & 3.35 & 1.65 \\
\hline (F) score & $\mathrm{SD}$ & 5.52 & 2.18 & 3.37 & 2.62 \\
\hline Physical & Mean & 6.62 & 1.45 & 5.40 & 1.50 \\
\hline (P) score & SD & 5.69 & 1.63 & 4.72 & 1.70 \\
\hline Emotional & Mean & 3.18 & 0.50 & 2.15 & 0.50 \\
\hline (E) score & SD & 4.70 & 1.05 & 3.08 & 1.35 \\
\hline
\end{tabular}

included a random selection of young normal healthy females with no voice complaints or strain on the voice. The two mean values would be in closer agreement if the mean of only the clerical group (level IV) in the present study is considered $(222.9 \mathrm{~Hz})$. This is because the clerks in the reproductive age group make up a group of young normal healthy females similar to the sample chosen for Till et al.'s study. This suggests that teachers (level II) in the present study have a lower $\mathrm{F}_{\mathrm{o}}$ which reduces the overall mean $\mathrm{F}_{\mathrm{o}}$ of the reproductive age group. This low value of the $\mathrm{F}_{\mathrm{o}}$ in teachers of reproductive age is probably due to constant professional voice use (all other factors being constant).

There is a reduction in $\mathrm{F}_{\mathrm{o}}$ for both professionals after menopause, a finding that agrees with Fawcus (1991), Boone (1997) and Sataloff (1998). The explanation for this reduction may be a rapid reduction in oestrogen (Titze, 1994) and an increase in androgen (Boone, 1997). The difference in $\mathrm{F}_{\mathrm{o}}$ before and after menopause was less in clerks, however. The smaller change in $\mathrm{F}_{\mathrm{o}}$ in teachers could either be because the $\mathrm{F}_{\mathrm{o}}$ was already lowered in the reproductive age group, or because the changes were forestalled as a result of regular voice use, or both. Although these hypotheses need further investigation, the above observations do suggest that prolonged use of the voice seems to affect the rate at which the fundamental frequency reduces after menopause.

NHR, which was higher in teachers, appears to correlate well with selfreported voice problems (as was evident on the VHI), a finding similar to that of Wolfe, Long, Youngblood, Henry and Olson (2002). Professional voice use does not seem to affect postmenopausal changes in NHR.

Brown, Morris and Hicks (1993) reported that the professional voice, unlike the untrained, is unaffected by the ageing process. Although their study pertained to singers (level I), the present study suggests that similar trends may be seen even in level II professionals, as the decrease in $\mathrm{SF}_{\mathrm{o}}\left(\right.$ and $\mathrm{F}_{\mathrm{o}}$ ) of teachers was smaller compared with clerks. However, since teachers in India are neither trained adequately at voice projection nor follow a good vocal hygiene programme, the factor resisting $\mathrm{SF}_{\mathrm{o}}$ change in teachers may not be training, but could definitely be vocal use experience.

The incidental finding that there was no significant difference in $\mathrm{SF}_{\mathrm{o}}$ obtained for reading and speaking tasks has clinical relevance. It implies that certain standardised stimuli could be used to elicit narration samples from those who cannot read, who make up a large subgroup of the Indian population.

\section{Aerodynamic parameters}

A probable explanation for the fact that teachers have a lower MPT could be excessive voice use at work. Short-term changes (Rantala et al., 2002; Mehta, 2005), if not reversed, may therefore progress to become long-term changes in MPT.

\section{Voice Handicap Index}

VHI (Jacobson et al., 1997) results yield much information in the light of the results obtained in relation to acoustic and aerodynamic parameters. It may be recalled that teachers are at an advantage compared with clerks in that they have a relatively smaller reduction in $\mathrm{F}_{\mathrm{o}}$ and $\mathrm{SF}_{\mathrm{o}}$ after menopause. Also there were no significant differences as compared to the clerical group in perturbation measures, $\mathrm{s} / \mathrm{z}$ ratio or $\mathrm{SF}_{\mathrm{o}}$. In spite of this, teachers reported greater vocal difficulty on the VHI. This underlines the importance of voice to their profession and also highlights how objective voice assessments coupled with a QoL measure would tremendously increase the face validity of our assessment. The lower VHI scores of postmenopausal women could be a cohort effect. An important observation that is apparent in Table VII was that the SDs of all the VHI scores were almost equal to or even greater than the means, unlike the small $\mathrm{SD}$ values of objective parameters such as $\mathrm{F}_{\mathrm{o}}, \mathrm{SF}_{\mathrm{o}}, \mathrm{MPT}$, etc. This demonstrates the large degree of variation that can be present in individual scores in spite of similar objective findings, and reaffirms the need to use a QoL measure to obtain client-specific information.

An interesting insight into menopausal voice changes was obtained when the findings were re-analysed using ANCOVA. On co-varying out the effects of age, the significant difference across menopause either decreased (VTI) or disappeared $\left(\mathrm{F}_{\mathrm{o}}\right)$. This gives statistical support to the statements by Samuel (1973) and Sataloff (1998) that ageing changes and menopausal changes are inseparable. However, it does not challenge the presence of menopausal changes. The presence of 'laryngopathia premenstrualis', the role that hormonal replacement therapy plays in counteracting menopausal changes, and the fact that corresponding changes are not seen in men around the age of 45 - 50 (Baken \& Orlikoff, 2000), place enough emphasis on the existence of postmenopausal changes. A peculiar result was obtained on ANCOVA for MPT. Where the difference in MPT of teachers and clerks was not statistically significant on two-way ANOVA, it became significant after co-varying out the variable of age. Age might therefore have been a factor, which earlier confounded the difference in MPT across profession. Hence the authors recommend that future cross-sectional studies on menopause should essentially consider using ANCOVA for statistical testing.

\section{Additional information obtained from the screening questionnaire}

Since the brief voice history questionnaire also had questions about nature and amount of voice use, a lot of incidental information could be obtained which would be of value for future research. The teachers reported having to use a loud voice for around $3-5$ hours a day. Vocal misuse in the form of shouting amounted to a total of around 30 minutes a day. Some of them had been pursuing singing as a hobby but had to discontinue it because of deterioration of their voices as a result of continual use. They also reported various skin and throat allergies to chalk dust, which they were regularly exposed to despite attempts to avoid it. All the schools visited had large classrooms, with capacity for about 60 students, again a condition detrimental to the voice. Teachers seem to be aware of the voice abuse and their poor environmental working conditions, and yet no efforts have been made to ameliorate these conditions.

\section{Conclusion}

Menopausal changes in voice, as a part of age-related changes, appear in all women, irrespective of their profession. However, the severity and rate of these changes are slightly different if the woman uses her voice regularly as part of her profession. Menopausal changes in some parameters of voice are accelerated while in others they are decelerated in teachers compared with clerks. Teachers are aware of their voice problems. However, lack of initiatives taken to make necessary changes, and lack of adequate knowledge of vocal hygiene, voice projection techniques, etc., increase their risk of developing vocal pathology. These findings could be put to practical use in the following ways:

1. The findings of this study could be used as norms pertaining to the range of variation in voice parameters of postmenopausal women. These norms in turn could serve to determine allowable limits of variation in voice parameters during voice assessment of this subpopulation of women.

2. The findings could aid research on voice changes in women using or not using hormonal replacement therapy, and also voice changes in 
women who have undergone natural menopause versus those who have undergone hysterectomy.

3. Studies on effects of training in efficient voice use, vocal hygiene and voice therapy on postmenopausal voice changes could stem from the information obtained in the present study.

4. The findings also bring to light the need to improve working conditions for teachers and have provisions similar to those given for other occupational disorders.

5. In future, research documenting effects of factors such as occupational voice use and menopause on voice, would be required to account for voice changes even in non-professional voice users, with the advent of speech recognition systems for day-to-day transactions.

6. The study also highlights the use of QoL measures as a means to make assessment and intervention a more meaningful and efficient process.

\section{References}

Abitbol, J., Abitbol, P., \& Abitbol, B. (1999). Sex hormones and the female voice. Journal of Voice, 13(3), 424-446.

Amir, O., Ashkenazi, O., Leibovitzh, T., Michael, O., Tavor, Y., \& Wolf, M. (2005). Applying the Voice Handicap Index (VHI) to dysphonic and nondysphonic Hebrew speakers. Journal of Voice, 20(2), 318-324.

Baken, R. J., \& Orlikoff, R. F. (2000). Clinical measurement of speech and voice (2nd ed.). San Diego: Singular Publishing Group.

Boone, D. R. (1997). The singing/acting voice in the mature adult. Journal of Voice, 11(2), 161-164.

Boulet, M. J., \& Oddens, B. J. (1996). Female voice changes around and after menopause an initial investigation. Mauritas, 23(1), 15-21. Retrieved 26 November 2007 from www. unboundmedicine/medline/ebm.

Brown, W. S., Morris, R. J., \& Hicks, D. M. (1993). Phonational profiles of female professional singers and nonsingers. Journal of Voice, 7(3), 219-223.

Buekers, R., Bierens, E., Kingma, H., \& Marres, E. H. M. A. (1995). Vocal load as measured by the voice accumulator. Folia Phoniatrica et Logopaedica, 47(5), 252-261.

Cheng, J., \& Woo, P. (2010). Correlation between Voice Handicap Index and voice laboratory measurements after phonosurgery. Ear, Nose and Throat Journal, 89(4), 183-188. Retrieved 1 August 2010 from http://www.thefreelibrary.com/ rrelation+between+the+Voice+Handicap+Index+and+voice+laboratory...-a0225936793

Colton, R. H., \& Casper, J. K. (1990). Understanding voice problems: A physiological perspective for diagnosis and treatment. Philadelphia: Williams \& Wilkins.

Conrad-Stoppler, M. (1999). Menopause. Retrieved 12 February 2008 from http://www. medterms.com/script/main/art.asp

Emerich, K. A., Hoover, C., \& Sataloff R. T. (1996). Journal of Singing, 52(4), 39-42. Retrieved 24 November 2008 from http://www.choralnet.org/resources

Fairbanks, G. (1960). Voice and articulation drillbook (2nd ed.). New York: Harper \& Row (pp 124-139). Retrieved 4 December 2008 from http://www.abdn.ac.uk/langling/resources

Fawcus, M. (1991). Hyperfunctional voice, the misuse and abuse syndrome. In M. Fawcus (Ed.), Voice disorders and their management (2nd ed., pp. 139-175). London: Chapman \& Hall.

Guimaraes, I., \& Abberton, E. (2004). An investigation of the voice handicap index with speakers of Portuguese - preliminary data. Journal of Voice 18(1), 71-79.

Jacobson, B. H., Johnson, A., Grywalsky, C., Silbergleit, A., Jacobson, G., Benninger, M. S., et al. (1997). The Voice Handicap Index: Development and validation. American Journal of Speech Language Pathology, 6(3), 66-70.

Koufman, J. A., \& Isaacson, G. (1991). The spectrum of vocal dysfunction. In: J. A. Koufman \& G. Isaacson (Eds.), Voice disorders. Otolaryngology Clinics of North America, 24, 985-988.

Lowell, S. Y., Barkmeier-Kraemer, J. M., Hoit, J. D., \& Story, B. H. (2008). Respiratory and laryngeal function during spontaneous speaking in teachers with voice disorders. Journal of Speech, Language and Hearing Research, 51(2), 333-349.
Ma, E. P.-M., \& Yiu, E. M.-L. (2001). Voice Activity and Participation Profile: Assessing the impact of voice disorders on daily activities. Journal of Speech, Language and Hearing Research, 44(3), 511-524.

Mehta, A. (2005). A comparative study of the vocal characteristics of primary and secondary school teachers in all-girls, all-boys and co-education set-ups. Unpublished master's dissertation, University of Mumbai, Mumbai, Maharashtra, India.

Meurer, E. M., Wender, M. C. O., Corleta, H. E., \& Capp, E. (2003). Phonoarticulatory variations of women in reproductive age and postmenopausal. Journal of Voice, 18(3), 369374.

Murry, T., Medrado, R., Hogikyan, N. D., \& Jonathan, E. A. (2004). Relationship between ratings of voice quality and quality of life measures. Journal of Voice, 18(2), 183-191.

Novak, A., Dlouha, O., Capkova, B., \& Vohradnik, M. (1991). Voice fatigue after theatre performance in actors. Folia Phoniatrica, 43(2), 74-78.

Ragini, M. (1986). Acoustic parameters of the voice on singing. In M. Jayaram \& S. R. Savithri (Eds.). (2002). Research at AIISH: Dissertation Abstracts (Vol. II, p. 94). Mysore: All India Institute of Speech and Hearing.

Rantala, L., Vilkman, E., \& Bloigu, R. (2002). Voice changes during work: Subjective complaints and objective measurements for female primary and secondary school teachers. Journal of Voice, 16(3), 344-355

Ravichandran, R. \& Rajendran, R. (2007). Perceived sources of stress among teachers. Journal of the Indian Academy of Applied Psychology, 33(1), 133-136.

Rosen, C. A., Murry, T., Zinn, A., Zullo, T., \& Sonbolian, M. (2000). Voice Handicap Index change following treatment of voice disorders. Journal of Voice, 14(4), 619-623.

Russell, A., Oates, J., \& Greenwood, K. 1998. Prevalence of voice problems in teachers. Journal of Voice, 12(4), 467-479.

Samuel, G. (1973). A study of the fundamental frequency of voice and natural frequency of an Indian population of different age ranges. In M. Jayaram, \& S. R. Savithri, (Eds). (2002). Research at AIISH: Dissertation abstracts (Vol. I, p. 16). Mysore: All India Institute of Speech and Hearing.

Sataloff, R. T. (1991). Professional Voice - The Science and Art of Clinical Care. New York: Raven Press.

Sataloff, R. T. (1998). Vocal health and pedagogy. San Diego: Singular Publishing Group, Inc.

Sheela, E. V. (1974). A comparative study of vocal parameters of trained and untrained singers. In M. Jayaram \& S. R. Savithri (Eds.). (2002). Research at AIISH: Dissertation abstracts (Vol I, p. 42). Mysore: All India Institute of Speech and Hearing.

Simberg, S., Sala, E., \& Ronnemaa, A. M. (2004). A comparison of the prevalence of vocal symptoms among teacher students and other university students. Journal of Voice, 18(3), 363-368.

Soderstein, M., Granqvist, S., Hammarberg, B., \& Szabo, A. (2002). Vocal behaviors and vocal loading factors for preschool teachers at work studied with binaural DAT recordings. Journal of Voice, 16(3), 356-371.

Stemple, J. C., Glaze, L. E., \& Gerdeman, B. K. (1995). Clinical voice pathology (2nd ed.). San Diego: Singular Publishing Group Inc.

Syamala, T. S., \& Sivakami, M. (2007, Jan 22). Indian women reaching menopause at 30: study The Times of India. Retrieved 26 November 2007 from www.timesofindia.indiatimes.com

Till, J. A., Jafari, M., Crumley, R. L., \& Law-Till, C. B. (1992). Effects of initial consonant, pneumotachographic mask, and oral pressure tube on vocal perturbation, harmonics-tonoise, and intensity measurements. Journal of Voice, 6, 217-223.

Timmermans, B., De Bodt, M. S., Wuyts, F. L., Boudewijins, A., Clement, G., Peeters, A., et al. (2002). Poor voice quality in future elite vocal performers and professional voice users. Journal of Voice, 16(3), 372-382.

Titze, I. R. (1994). Principles of voice production. New Jersey: Prentice Hall.

Wheeler, K. M., Collins, S. P., \& Sapienza, C. M. (2006). The relationship between VHI scores and specific acoustic measures of mildly disordered voice population. Journal of Voice, 20(2), 308-317.

Wolfe, V., Long, J., Youngblood, H. C., Henry, W., \& Olson, M. S. (2002). Vocal parameters of aerobic instructors with and without voice problems. Journal of Voice, 16(1), 52-60.

Yiu, E. M-L. (2002). Impact and prevention of voice problems in the teaching profession: Embracing the consumers' view. Journal of Voice, 16(2), 215-229.

Zeine, L., \& Waltar, K. L. (2002). The voice and its care: Survey findings from actors' perspectives. Journal of Voice, 16(2), 229-243. 